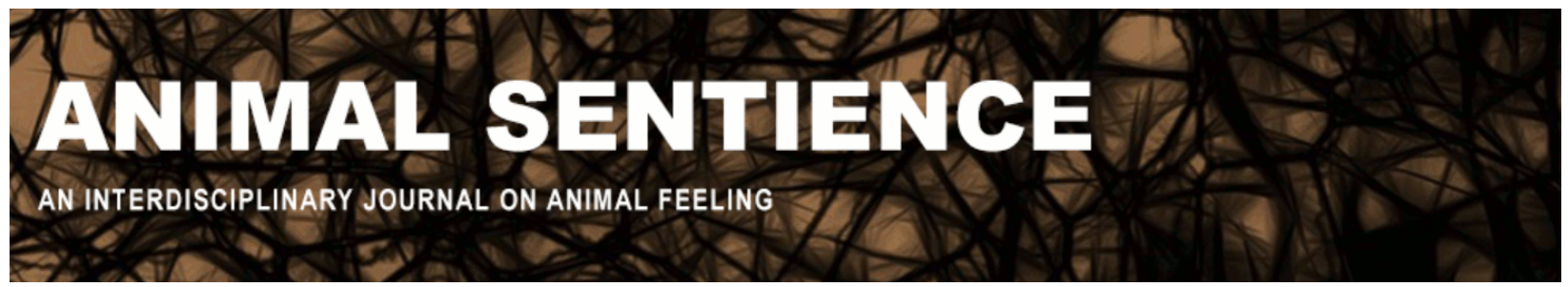

Bottomley, Ewan and Loughnan, Steve (2017) Chickening out of change: Will knowing more about thinking chickens change public perceptions?. Animal Sentience 17(8)

DOI: $10.51291 / 2377-7478.1256$

Date of submission: 2017-11-16

Date of acceptance: 2017-11-22

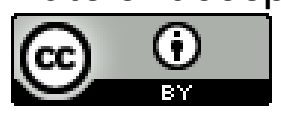




\title{
Chickening out of change: \\ Will knowing more about thinking chickens change public perceptions?
}

Commentary on Marino on Thinking Chickens

\author{
Ewan Bottomley \\ Department of Psychology \\ University of Edinburgh \\ Steve Loughnan \\ Department of Psychology \\ University of Edinburgh
}

\begin{abstract}
This commentary examines the next step in Marino's target article - changing people's attitudes and beliefs about chickens. The scientific case seems clear: chickens are far more complex, psychologically and socially, than originally thought. Marino suggests we use this information to make people feel uncomfortable about their dietary choices in the hope of changing them. We review the psychological literature, examining how people maintain meat consumption despite the clash with their moral beliefs (the "meat paradox"). This work highlights the important gap between what science knows about animals and what people think about animals.
\end{abstract}

Ewan Bottomley is a researcher at the University of Edinburgh. His work focuses on attributions of mind and moral concern.

steve-loughnan.squarespace.com/

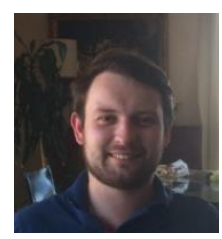

Steve Loughnan is a Reader in Psychology at the University of Edinburgh. His work focuses on the psychology of eating animals. steve-loughnan.squarespace.com/

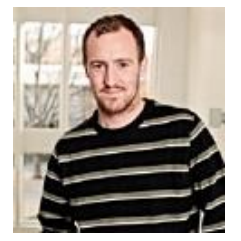

There is a lot to like about Marino's (2017b) articles. She neatly and cogently summarizes the literature of the psychological and social lives of chickens. As guests in this field we - much like the experts (e.g., Freire \& Hazel, 2017) - were left in little doubt that chickens have attributes far closer to complex mammals than is routinely recognized. In her summary for Animal Sentience, Marino (2017a) points to two important gaps in our thinking about chickens. The first is a scientific gap; despite evidence for the complexity of chickens, which she summarizes compellingly, the field remains preoccupied with the 'management' of chickens as commodities. This is important, but the second gap interests us more: the general public misunderstand and underestimate the psychological and social lives of chickens. Like Marino, we think that is not casual ignorance but rather a way to help people feel good about their dietary choices. Whereas the scientific gap can 
be addressed with rigorous research, we suggest that it is less clear how we can use this information to change public beliefs.

Chickens occupy an unusual place in the psychological landscape of meat. Chicken is the most commonly consumed meat in the US, and the most commonly consumed by former vegetarians and vegans (Humane Research Council, 2014). A 2012 study asked people to rate thirty-two animals on a range of gustatory and psychological dimensions. It found that the chickens were considered the most edible of all (Bastian, Loughnan, Haslam, \& Radke, 2012). Unlike every other terrestrial animal who scored above average on edibility, the chicken was deemed below average in mind (see Figure 1). This makes chickens potentially the most difficult terrestrial animal to convince people to stop eating, as they are seen as not only highly edible but relatively mindless.

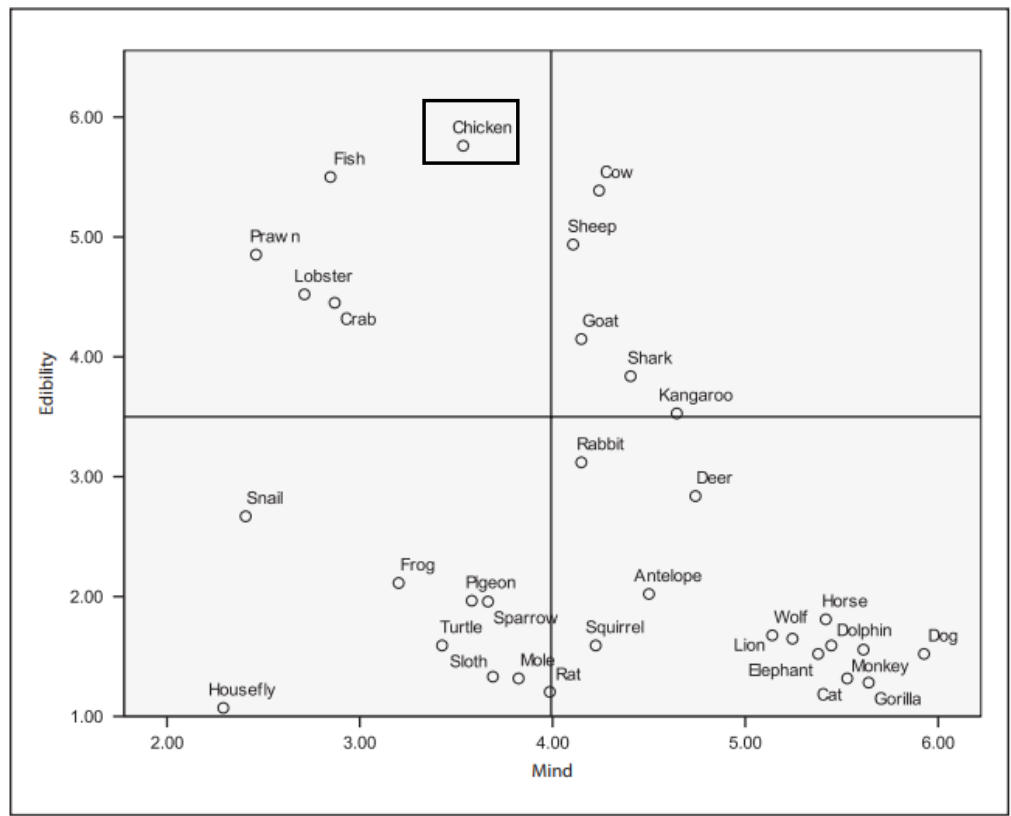

Figure 1. Edibility and mind ratings for 32 animals

(from Bastian et al. 2012, chicken emphasis added)

Despite this challenge, Marino's article provides plenty of evidence for convincing people that chickens have considerably more complex minds than they think. Given the robust association between the amount of mind attributed to an animal and the moral concern we feel toward it (Bastian et al., 2012; Gray, Gray, \& Wegner, 2007), Marino's conclusion that increasing awareness of chickens' minds will reduce consumption seems correct.

The simplest approach to addressing public ignorance about the minds of chickens would be to inform people about the reality of animals' high intelligence; this does make us think that the animal is more intelligent, even when it is an animal we eat (e.g., pigs) (Piazza \& Loughnan, 2017). Unfortunately, although the knowledge of the intelligence of victims is indeed linked to moral concern in general (Gray, Gray, \& Wegner, 2007), and particularly in the case of animals (Bastian et al., 2012; Bratanova, Loughnan, \& Bastian, 2011), when people learn that an animal they personally eat is intelligent, it fails to move moral concern. Put simply, it's not OK to eat smart animals, except when I am the one doing the eating. For psychologists this inconsistency is not 
surprising - we have carefully mapped out how people's motivation to see themselves as moral and 'good' interferes with behavioral change (e.g., Festinger, 1957) and facilitates ongoing immorality (cf. Dunning, 1999). For Instance, the consumption of meat reduces moral concern for the animals involved, as consumers justify their own behavior (Loughnan, Haslam, \& Bastian, 2010). Omnivorous readers of Marino's article may well find themselves viewing chickens as more intelligent, but the psychological findings suggest they will not see chickens as any more deserving of moral treatment.

An alternative approach might be to let people discover for themselves the remarkable minds of chickens. Perhaps observing or interacting directly with chickens in a more naturalistic environment will lead us to conclude that they are more intelligent and thus more deserving of our protection and care. Interacting with animals does increase our ascription of complexity to their minds (Loughnan, Davies, Antal, \& Zaharieva, 2017), and this is true of chickens too (Hazel, O'Dwyer, \& Ryan, 2015). Unfortunately, there is emerging evidence that this too fails to translate into reduced willingness to eat them (Loughnan et al., 2017). Meeting chickens may increase how intelligent and social we believe them to be, but may not make us care about them more.

This summary paints a rather bleak picture. Marino's target article may - indeed, should spur researchers to pay more attention to the remarkable lives of chickens. But how can we translate this into improving their lives? We now have a wealth of evidence and an understanding that the simplest paths to attitude and belief change are unlikely to work (cf. Bastian \& Loughnan, 2016). One promising future direction may be to make the link between the intelligent animal and the meat on the plate inescapable. When presented with clear evidence for this link, we know that people will seek to undermine the intelligence of meat animals (Bastian et al., 2012). What happens when we don't let them? What happens when a chicken's mind and social world are affirmed in the face of a roast, or a bucket of drumsticks? Alternatively, could we use the freshly created awareness of farm animals' rich mental lives, forged by either journal article (Piazza \& Loughnan, 2017) or real-world contact (Loughnan et al., 2017), to then show people graphic evidence of farm animal suffering? Perhaps, prior work has missed the link between mind and meat: the suffering of the animal. We see translating the excellent work on animal sentience into behavioral change as a central challenge for the field.

\section{References}

Bastian, B., \& Loughnan, S. (2016). Resolving the meat paradox: A motivational account of morally troublesome behavior and its maintenance. Personality and Social Psychology Review, 21(3), 278-299.

Bastian, B., Loughnan, S., Haslam, N., \& Radke, H. R. (2012). Don't mind meat? The denial of mind to animals used for human consumption. Personality and Social Psychology Bulletin, 38(2), 247-256.

Bratanova, B., Loughnan, S., \& Bastian, B. (2011). The effect of categorization as food on the perceived moral standing of animals. Appetite, 57, 193-196.

Dunning, D. (1999). A newer look: Motivated social cognition and the schematic representations of social concepts. Psychological Inquiry, 10, 1-11.

Festinger, L. (1957). A theory of cognitive dissonance. Stanford University Press, Stanford, CA. 
Freire, R., \& Hazel, S. J. (2017). Are chicken minds special?. Animal Sentience 17(4).

Gray, H., Gray, K., \& Wegner, D. (2007). Dimensions of mind perception. Science, 315(5812), 619-621.

Hazel, S. J., O’Dwyer, L., \& Ryan, T. (2015). "Chickens are a lot smarter than I originally thought": Changes in student attitudes to chickens following a chicken training class. Animals, 5(3), 821-837.

Humane Research Council. (2014). Study of current and former vegetarians and vegans. Initial findings.

Loughnan, S., Davies, T., Antal, K., \& Zaharieva, E. (2017). Meet your meat: Contact increases attributions of mind to farmed animals but does not alter meat-eating. Manuscript under review.

Loughnan, S., Haslam, N., \& Bastian, B. (2010). The role of meat consumption in the denial of moral status and mind to meat animals. Appetite, 55, 156-159.

Marino, L. (2017a). The inconvenient truth about thinking chickens. Animal Sentience 17(1).

Marino, L. (2017b). Thinking chickens: A literature review of cognition, emotion, and behavior in the domestic chicken. Animal Cognition, 20(2), 127-141.

Piazza, J., \& Loughnan, S. (2017). When meat gets personal, animals' minds matter less: Motivated use of intelligence information in judgments of moral standing. Social and Personality Psychological Science, 7, 867-874. 